\title{
Pareto-Improving Unemployment Policies
}

J. Lingens and K. Waelde

Discussion Paper 2005-33

\section{Département des Sciences Économiques de l'Université catholique de Louvain}




\title{
Pareto-Improving Unemployment Policies
}

\author{
Jörg Lingens ${ }^{(a)}$ and Klaus Wälde ${ }^{(b), 1}$ \\ (a) University of Regensburg and ${ }^{(b)}$ University of Würzburg \\ CESifo and UCL Louvain la Neuve
}

\begin{abstract}
August 2005
We investigate how continental European unemployment can be reduced without reducing unemployment benefits and without reducing the net income of low-wage earners. Lower unemployment replacement rates reduce unemployment, the net wage and unemployment benefits. A lower tax on labour increases net wages and - for certain benefit-systems - unemployment benefits as well. Combining these two policies allows to reduce unemployment in countries with "net-Bismarck" and Beveridge systems without reducing net income of workers or the unemployed. Such a policy becomes self-financing under realistic parameter constellations when taxes are reduced only for low-income workers.
\end{abstract}

Keywords: Inequality, Unemployment, Taxation, Policy reform JEL classification numbers: J380, J510, H230, E600

\footnotetext{
${ }^{1}$ Jörg Lingens: Department of Economics, University of Regensburg, 93051 Regensburg, Germany. Phone +49.941.943-2722, Fax +49.941.943-4941, Joerg.Lingens@wiwi.uni-regensburg.de. Klaus Wälde (corresponding author): Department of Economics, University of Würzburg, 97070 Würzburg, Germany, klaus@waelde.com, http://www.waelde.com, Phone + 49.931.31-2950, Fax + 49.931.31-2671. We are grateful to Sascha von Berchem, Günter Lang, Ned Phelps, Karl Pichelmann, Werner Roeger, Rick van der Ploeg, seminar participants at the Universities of Augsburg, Dortmund, Dresden, the European Commission (DG ECFIN) in Brussels, participants of the 2005 Public Finance CESifo conference and the 2005 WPEG conference in York and especially Bruno Van der Linden for comments and discussions. This research is part of a programme supported by the Belgian government (Poles d'Attraction inter-universitaires PAI P5/21).
} 


\section{Introduction}

Many European countries are still struggling with high unemployment rates. Sufficiently many analysts agree on two facts: Unemployment is heavily concentrated among low-skill individuals and demand for low-skill individuals could be increased by reducing their labour costs. There is little consensus on how to reduce labour costs. Some argue that net wages need to fall, others suggest reductions in tax burdens while still others propose a reduction in social security contributions.

The starting point of this paper is a certain concern for equality. This could be justified on pure egalitarian grounds, on considerations based on social welfare maximization (where income uncertainty would require $100 \%$ insurance under risk aversion unless there is moral hazard) or on efficiency arguments (less inequality implies less crime; see e.g. Thorbecke and Charumilind, 2002, for a survey). This could also be justified by arguing that policy recommendations to fight unemployment will be adopted in the political process more easily when various interest groups in a society are treated equally well. Whatever the specific reasoning, the question concerning unemployment of low-skilled would always be whether unemployment can be reduced without decreasing the net wage of low skilled or net benefits of the unemployed. This is the question of this paper.

Given that certain egalitarian concerns play a role in the political process, this question is of major importance for many continental European economies like e.g. Germany, France or Italy. Other countries were already relatively successful in reducing unemployment, one example being the UK, but also the Netherlands (see e.g. Pissarides, 2003 on the UK or Nickell, Nunziata and Ochel, 2005, for an OECD perspective). This adjustment in unemployment came at a cost, however, as the following figure shows.

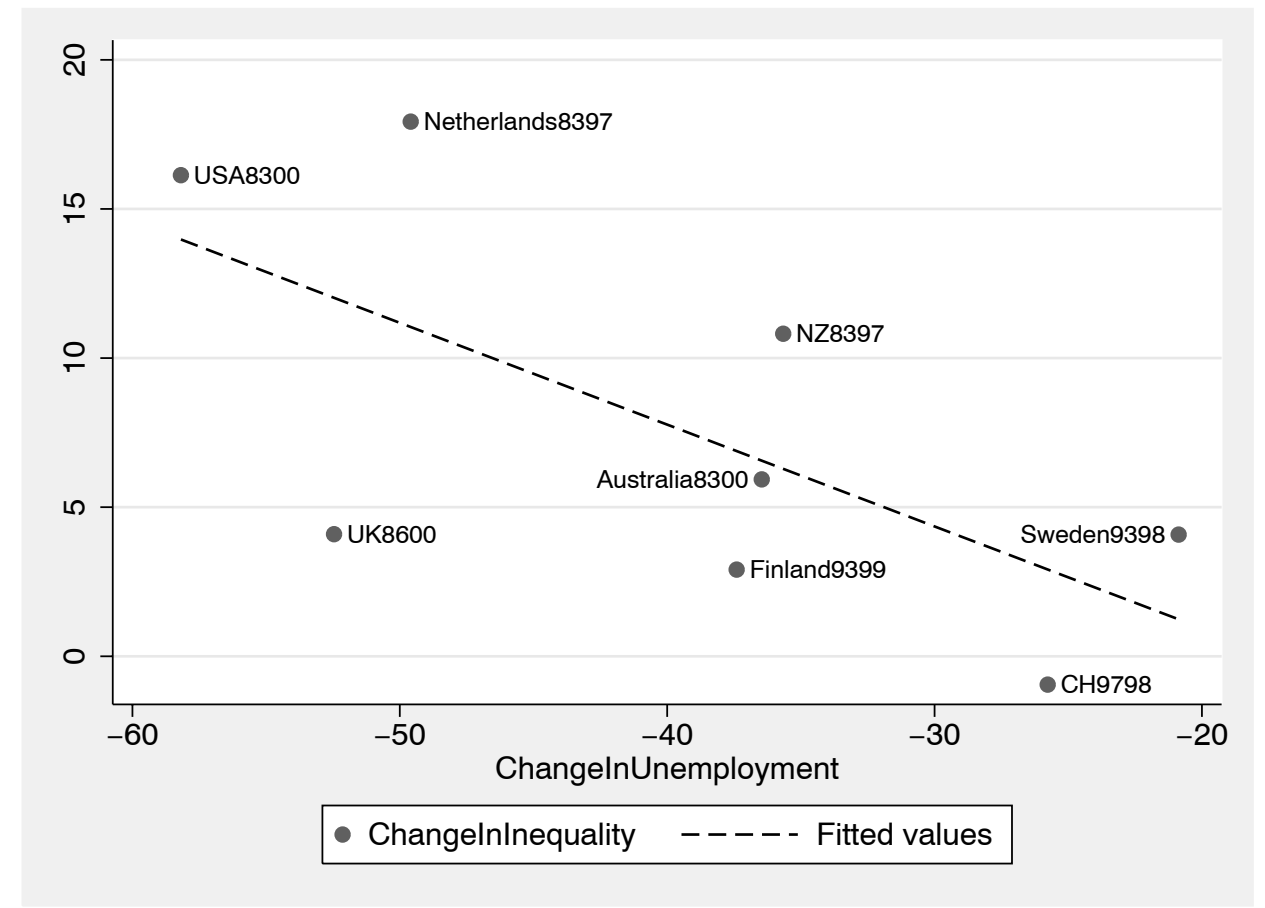

Figure 1 Increase in wage inequality in countries that were successful in reducing unemployment (all changes in percent) 
The horizontal axis shows changes in unemployment rates, the vertical axis shows changes in inequality as measured by the increase in the ratio of the 90th percentile gross wage $w 90$ and the 10th percentile gross wage $w 10$. The data on wage income by percentiles comes from OECD (2004), unemployment rates are from the OECD as well. Among countries for which inequality data is available, we chose those countries who were successful in reducing unemployment. We computed the change in the $w 90 / w 10$ ratio between the last date when information on wage percentiles is available and the year when the unemployment rate was at a maximum. The dot Netherlands8397 therefore shows the decrease in unemployment in the Netherlands between 1983 and 1997 and the contemporaneous increase in the wage ratio. This figure shows clearly that countries that were most successful in reducing unemployment were at the same time countries that experienced the strongest increase in gross wage inequality. To the extent that the time periods considered here are not periods where tax reforms were simultaneously put in place that favour net incomes of low-skilled, this figure also suggests that a reduction in unemployment came along with an increase in net wage inequality.

There are two questions arising from this figure: First, can countries like France, Germany and Italy reduce unemployment without simultaneously having to accept more net-wage inequality or even accept a reduction in real net wages of low-income groups? Second, can countries that were successful in reducing unemployment and that did experience a rise in net wage inequality correct this effect without increasing unemployment again? ${ }^{2}$ To find answers to these questions, we use the simplest possible theoretical framework. Our static model economy, presented in section 2, produces one homogenous good by employing high-skill and low-skill workers. Only the low-skilled are organised in unions. ${ }^{3}$ Unions ration labour and thereby cause unemployment. ${ }^{4}$ The government provides unemployment benefits, which amplifies unemployment, and taxes labour. Taxation should be understood in a broad sense and includes labour taxes per se and social security contributions. In equilibrium, there will be three groups: the high-skilled, employed low-skilled and unemployed low-skilled. As unemployment benefits in OECD countries are computed in at least three different ways (OECD, 2002), we distinguish between institutional setups that can be called Beveridge system (unemployment payments are wage independent), net-Bismarck system (unemployment payments are proportional to net wages) and gross-Bismarck systems (unemployment payments are proportional to gross wages).

The policy experiments we perform have as objective to (i) reduce unemployment, (ii) keep either the net-wage of a worker or the net payment to an unemployed worker at its current level, (iii) preserve the current budget balance of the government, i.e. policy reforms must be self-financing and (iv) preserve incentives to become skilled. As instruments,

\footnotetext{
${ }^{2}$ Taking the UK as example, Clark and Leicester (2004) or earlier Johnson and Webb (1993) analyzed the effect of tax and benefit reforms on net income inequality. They find that with plausible assumptions the reforms did indeed considerably contribute to the rise in net-income inequality. If parts of this reform also helped in reducing unemployment, one could ask whether reforms can be corrected such that unemployment remains at low levels and that net income of low-wage groups rises. Nickell (2004) analyses the rise in poverty in the UK.

${ }^{3}$ When defining skill by educational level, empirical support for this assumption is fairly overwhelming (e.g. Schnabel, 2002). See Sørensen (1997, p. 238) for a similar assumption.

${ }^{4}$ We believe that our basic message is robust to changes in the cause of unemployment (e.g. efficiency wages, insider-outsider aspects, search unemployment).
} 
we use the tax rate on labour and either the replacement rate in Bismarck countries or unemployment benefits directly. ${ }^{5}$ We also vary the progressiveness of labour taxation. A policy reform that preserves net wages of workers will be called an equality-preserving reform (EPR), a reform that preservers net payments to the unemployed will be called ambitious EPR. ${ }^{6}$ A policy that reduces unemployment, does not decrease net income of all labour groups and is self-financing is, by definition, a Pareto-improving policy reform. We find that Pareto-improving reforms exist.

Independently of what system we look at, section 3 shows that a reduction in payments to the unemployed and a contemporaneous reduction in labour taxes reduces unemployment and keeps net wages of workers at the pre-reform level. Such an EPR can most easily be illustrated for net-Bismarck systems: reducing the replacement rate increases employment and both the gross and the net wage fall. As in net-Bismarck systems the labour tax has no effect on the gross wage, the tax can be reduced such that the decrease due to the replacement rate is just compensated. In other systems, where taxes affect employment, the mechanism is not as clear-cut but possible in principle. In some cases, depending on parameter values, an EPR is also self-financing.

Needless to say that an EPR generally hurts the unemployed: the reduction in the labour tax is designed to compensate workers for lower gross wages, the unemployed are directly affected by the reduction in the replacement rate whose effect on unemployment payments is usually not compensated for by lower taxation. Decreasing net payments to the unemployed could be avoided in net-Bismarck systems by reducing taxes on labour even further. An ambitious EPR would result. It can not be avoided, however, in gross-Bismarck systems. In gross-Bismarck systems, payments to the unemployed and net wages move in opposite directions when the labour tax rate is changed. An EPR therefore contradicts an ambitious EPR - the gross-Bismarck system could therefore be called relatively "distribution -unfriendly". In Beveridge systems, an ambitious EPR is possible by reducing the tax on labour.

When analyzing the effects of EPRs and ambitious EPRs in these three systems in section 4 , they are self-financing only in "rare cases". EPRs are generally self-financing for a larger set of parameters characterizing the share of skilled workers in the work force and the prereform tax rate. Ambitious EPRs often require implausible parameter assumptions in order to be self-financing. Policy reforms that are based on broad tax reductions in order to alleviate net-wage losses following cuts in replacement rates or benefit payments are therefore difficult to be put in place.

We therefore extend policy options in section 5 by allowing to reduce labour taxes only

\footnotetext{
${ }^{5}$ These are two of the measures which the empirical literature on the effect of institutions on unemployment uses regularily. See e.g. Belot and van Ours (2004), Blanchard and Wolfers (2000) or Nickell, Nunziata and Ochel (2005). The effects of institutions on wage inequality are studied e.g. by Kahn (2000) or Koeniger, Nunziata and Leonardi (2004). Labour taxes are generally found to have a negative impact on unemployment while the replacement rate is not always significant. The duration of unemployment payments, however, is highly significant. As we use a static model, we view our theoretical replacement rate as a joint present-value measure of the level and the length of unemployment payments. See the conclusion for further discussion.

${ }^{6}$ Our objective is to keep welfare of individuals at certain levels that are not affected by some reform. In an envy-free world (which we model), this requires constant net income and is independent of other individuals' welfare. Hence, we somewhat misuse the term 'equality' as equality is a relative concept and we are analysing absolute levels.
} 
for the low-skilled and keeping them at the current level for high-skilled workers. It turns out that with this way of introducing more progressiveness in taxation, the EPR for net-Bismarck systems is always self-financing and that the ambitious EPR for net-Bismarck systems is selffinancing for realistic parameter values. Reducing unemployment in net-Bismarck countries at unchanged net income of the unemployed is possible without increasing the government's budget deficit.

As making taxation more progressive does not improve the policy problems in grossBismarck systems, we analyse whether gross-Bismarck systems can be replaced by a netBismarck system without affecting the government's budget balance, the unemployment rate and payments to the unemployed (i.e., more generally speaking, without changing the factor allocation). As it turns out that this can be done by simply adjusting one policy parameter, the replacement rate, an EPR or an ambitious EPR is most likely when first adopting the most "distribution-friendly" system, i.e. the system that allows for Pareto-improving and unemployment-reducing policy reforms, and then "choose" the desired unemployment rate. Hence, reducing unemployment in a Pareto-improving way is possible in gross-Bismarck countries as well.

We finally ask whether our policy proposals preserve existing relative net wages. This is important as we would like to avoid that incentives to accumulate human capital (even though not explicitly modelled) decrease. We find that in net-Bismarck systems a selffinancing ambitious EPR increases, under realistic parameter values, net-wage inequality. Hence, unemployment can be reduced, net-income of unemployed or employed does not decrease, the government budget remains balanced and learning incentives are preserved. Reasonable Pareto-improving polices to fight unemployment exist.

Due to the simplicity of our modelling approach, various model components have been used by other authors before who have also analysed the effect of taxation and benefits on unemployment or unemployment and inequality (e.g. Sørensen, 1997; Pissarides, 1998; Cahuc and Lehmann, 2000; Hoon and Phelps, 2003; Kaas and von Thadden, 2004, van der Linden, 2004; Bovenberg, 2005. For an excellent overview, see Cahuc and Zylberberg, 2004). Compared to these papers, the main contribution of our approach is twofold. First, we derive policy reforms that allow to achieve multiple objectives: Reduce unemployment while keeping income of certain groups constant. Technically speaking, we undertake a comparative static analysis under equality constraints. These constraints were not explicitly analysed in previous work; they are, however, central for many policy makers. Second, we explicitly analyse the budgetary implications of our reforms. ${ }^{7}$ While it is important to understand how unemployment and equality are affected by policy changes, the chance for any reform proposal to be implemented crucially depends on the effect these reforms have on the budget balance of the government. We show under which conditions our policy reforms are self-financing. ${ }^{8}$

From a policy perspective, there are various proposals that aim at preserving certain minimum incomes without causing too strong efficiency losses. Most of these proposals

\footnotetext{
${ }^{7}$ Hanushek, Leung and Yilmaz (2003) also require a balanced budget in their analysis of how different transfer mechanisms affect the income distribution in a competitive full-employment model.

${ }^{8}$ There is evidence that programms that provide tax incentives to increase employment can be selffinancing indeed, see Michalopoulosa, Robins and Card (2005). Even though this is micro-economic evidence, it suggests that the search for self-financing reforms on the aggregate level is worth being undertaken.
} 
were developed for countries like the US where the institutional background differs from Europe. The most well-known is probably the negative income tax (NIT) proposal going back to Friedman (1962). Its main objective is to provide low-income workers with some guaranteed basic income without reducing incentives to work. ${ }^{9}$ An alternative approach is a wage-subsidy to workers or to firms (e.g. Snower, 1994 or Phelps, 1994, 1997), known as Earned Income Tax Credits (EITC). ${ }^{10}$

The NIT or EITC proposals are sometimes applied to continental European countries. Unemployment could be reduced without increasing inequality, the argument at least implicitly goes, if on the one hand, the institutional background in, say, France, Germany and Italy is changed, i.e. if e.g. bargaining power of unions is reduced, and, on the other hand, if wage subsidies or negative income taxes are introduced. Such an approach has several disadvantages, however. First, it is politically not credible; individuals proposing a reduction in union power are typically not those who favour certain minimum net-wage levels. Second, while some institutions would be removed, new institutions would have to be created (apart from countries that already have e.g. certain forms of subsidies to low-wage earners). On a continent caught by many institutional details, this is not desirable. Further, as Snower (1994) and Phelps (1994) write themselves, these proposals are not necessarily equality preserving and the question of self-financing has not been investigated. We therefore believe that it is useful to preserve the existing institutional setup in many European countries and use existing instruments to reduce unemployment without increasing inequality.

A further important difference of our proposal compared to the NIT is the view about the origins of unemployment. If a certain income is guaranteed to individuals independently of whether they work, unemployment rates for low-income groups rise as, following the general argument, it is not rational for agents to accept a job that pays lower net income than, say, social welfare payments. While any increase in work incentives at unchanged net-income is desirable, we think that unemployment caused by social welfare payments is only part of the story. Only about $1 / 3$ of the unemployed (e.g. in Germany in September 2003) had been unemployed for 1 year or more. The majority therefore receives unemployment insurance payments and we capture this latter type of unemployment by rationing effects due to e.g. union wage setting (which is especially relevant for continental Europe). ${ }^{11}$ It turns out that in this setup a reduction in social welfare payments or income of the unemployed is not required to reduce unemployment in a self-financing way.

A policy paper with a European institutional background is by Sørensen (1997) (see also Kleven and Sørensen, 2004). He undertakes a careful CGE analysis of the effects of reducing the tax burden on the low-skilled by reducing tax rates of this group or goods which use low-skilled intensively. He obtains a balanced budget by increasing other taxes. Such an approach would also preserve or even increase wages of low-skilled and unemployed

\footnotetext{
${ }^{9} \mathrm{~A}$ less expensive variety is a targeted NIT, where only a certain group falls under a NIT scheme. This could be the long-term unemployed (Jerger and Sperman, 1997) or those participating in the labour market (Van der Linden, 2004).

${ }^{10}$ Both concepts and their implementation in US welfare policy are presented by Moffitt (2003). Saez (2002) analyses which of these concepts is preferable from an optimal taxation perspective. Different implementations of the Earned-Income Tax Credit in OECD countries are presented by EEAG (2002).

${ }^{11}$ Unemployment in European countries is certainly also due to efficiency wage aspects. The effect of low-wage subsidies in such a framework is analysed in Hoon and Phelps (2003, sect. 2).
} 
and our paper in this sense shares the same spirit. We believe, however, that reducing the unemployment rate will help to reduce unemployment more than just reducing taxes and therefore include the effect of lower replacement rates in our analysis as well.

Finally, the same concern for not reducing the welfare state in an inappropriate way is shared by van der Ploeg (2005a). He shows that distributive and social policies do not necessarily harm an economy in terms of employment or welfare in second-best worlds. More "intelligent" unemployment payments rather than reducing them on a broad scale could be a better approach to policy reforms: Abolishing e.g. unconditional unemployment benefits and introducing conditional benefits that are paid only to involuntarily unemployed but not to those who shirk or quit voluntarily can increase employment (see also van der Ploeg, 2005b). Unfortunately, his approach suffers from strong informational requirements (as the author discusses in his conclusion). In our proposal, we use simple existing policy instruments which can easily be adjusted such that desired policy outcomes result.

\section{The model}

\subsection{Technology}

Imagine an economy where an aggregate technology is used for producing a consumption good. Factors of production are human capital and labour. The two groups of labour can be defined according to educational achievement or their labour income. The aggregate technology is given by

$$
Y=F(H, L),
$$

where $F($.$) has constant returns to scale. Firms act under perfect competition and their$ implicit labour demand functions are

$$
F_{L}(H, L)=w_{L}, \quad F_{H}(H, L)=w_{H},
$$

where gross factor rewards, including taxes and social security contributions, are $w_{H}$ and $w_{L}$.

Most of the time, we work with a CES production function. Normalising a TFP measure to unity and denoting the share-parameter by $\beta$, we have

$$
Y=\left(\beta H^{\theta}+(1-\beta) L^{\theta}\right)^{1 / \theta}
$$

where $\theta$ determines the elasticity of substitution $\sigma$ between human capital and labour,

$$
\left.\begin{array}{c}
1>\theta>0 \\
\theta=0 \\
\theta<0
\end{array}\right\} \Leftrightarrow \sigma \equiv \frac{1}{1-\theta} \gtreqless 1 .
$$

In some cases, we also restrict attention to the Cobb-Douglas (CD) case, where, for $\theta=0$ in $(3)$,

$$
Y=H^{\beta} L^{1-\beta}
$$




\subsection{Households}

There are two types of households. The high-skill households and the low-skill households. Labour supply of the high-skilled is determined by utility maximization. Their preferences are captured by $U=U(C, H)$, where $U($.$) has the usual properties. The budget restriction$ of such a household is $\left(1-\tau_{H}\right) w_{H} H=C$. There are $L_{s}$ households that are less skilled and their preferences depend on consumption only; employment $L$ is determined by unions and will be presented in the next subsection. ${ }^{12}$

Utility maximizing labour supply of highly-skilled is determined, apart from parameters, by net wages only. It can be expressed by an implicit human-capital supply curve $w_{H}^{s}$ with the tax on high-skill income and human capital as arguments,

$$
H=H\left(\left(1-\tau_{H}\right) w_{H}\right) \Leftrightarrow w_{H}=w_{H}^{s}\left(\tau_{H}, H\right)
$$

Assuming a CES utility function of the form $U=\left(\gamma C^{\lambda}+(1-\gamma)(T-H)^{\lambda}\right)^{1 / \lambda}$, we get a human capital supply curve of (app. 9.1)

$$
w_{H}=\frac{1}{1-\tau_{H}}\left(\frac{1-\gamma}{\gamma}\right)^{1 / \lambda}\left(\frac{T-H}{H}\right)^{(\lambda-1) / \lambda} .
$$

Human capital supply increases in the net wage when $0<\lambda<1$ and decreases when $\lambda<0$. In what follows, we will always assume an upward sloping supply curve for human capital, i.e. $0<\lambda<1$.

With a CD example like $U=C^{\gamma}(T-H)^{1-\gamma}$, human capital supply is fix (app. 9.1),

$$
H=\gamma T \text {. }
$$

\subsection{Unions}

Low-skill individuals are organised in unions. Unions operate at the level of a sector or firm $i$. The objective of the unions is to maximize net labour income of its members in excess of alternative income a worker would earn in case of employment in other firms or unemployment. Union preferences can be expressed by $\left(1-\tau_{L}\right) w_{i} L_{i}+B_{i}\left[M_{i}-L_{i}\right]$, where $w_{i}$ is the gross wage of low-skill workers in sector $i$ and $B_{i}$ and $M_{i}$ denote alternative income and the number of members, respectively. Taking $B_{i}$ and $M_{i}$ as parametric, the objective function can be expressed in the more simple form $u_{i}=L_{i}\left(w_{i}\right)\left[\left(1-\tau_{L}\right) w_{i}-B_{i}\right]$. Maximization subject to labour demand in sector $i$ similar to (2) yields (app. 9.2) the usual markup of the net wage over alternative income ${ }^{13}$,

$$
\left(1-\tau_{L}\right) w_{i}=B_{i} /\left(1-\eta_{L}^{-1}\right)
$$

\footnotetext{
${ }^{12}$ An earlier draft had endogenous labour supply of low-skilled in addition to union labour rationing. While principles remained the same, tractability became much more difficult.

${ }^{13}$ This markup expressions requires a labour demand elasticity that is larger than unity, $\eta_{L}>1$. This is due to the monopoly union setup. More elaborate approaches to unions than this simple right-to-manage model exist. Again, we believe that our main results are valid for other specifications as well.
} 
where the markup $\left(1-\eta_{L}^{-1}\right)^{-1}$ is the lower, the larger the wage elasticity $\eta_{L}$ of demand for low-skilled,

$$
\eta_{L} \equiv-\frac{\partial L_{i}\left(w_{i}\right)}{\partial w_{i}} \frac{w_{i}}{L_{i}\left(w_{i}\right)}>0
$$

Alternative income $B_{i}$ of workers is given by income from other sectors or from unemployment benefits $b$ when not employed. Assuming identical probabilities for a worker not employed in $i$ to find work in another sector $s$ or to become unemployed, alternative income amounts to $B_{i}=\Sigma_{j=1}^{s}\left(1-\tau_{L}\right) w_{j} \frac{L_{j}}{L_{s}}+b \frac{L_{s}-L}{L_{s}}$. In a symmetric equilibrium, where every firm and every union behaves the same, the alternative income is given by

$$
B_{i}=\left(1-\tau_{L}\right) w_{L} \frac{\Sigma_{j=1}^{s} L_{j}}{L_{s}}+b \frac{L_{s}-L}{L_{s}} \equiv\left(1-\tau_{L}\right) w_{L}[1-u]+b u
$$

where the second equality defines the unemployment rate $u$ of low-skilled.

To determine the unemployment rate, we need the wage setting curve of the unions. This curve shows the wage the unions will set as a function of low-skill employment, hence as a function of the overall low-skill labour market situation. Plugging (11) into (9) gives the general wage setting curve,

$$
\left(1-\tau_{L}\right) w_{L}=\left(1-\eta_{L}^{-1}\right)^{-1}\left(\left(1-\tau_{L}\right) w_{L}[1-u]+b u\right)
$$

Since the wage setting curve is a function of the unemployment benefit $b$, we get different wage setting curves for the different institutional settings. They are specified in the next subsection.

For later purposes, we compute the demand elasticity $\eta_{L}$ for our CES and CD technologies. When we assume unions to take $H$ as parametric, we compute $\eta_{L}^{-1}$ from the CES version of (2) and get (app. 9.3 $)^{14}$

$$
\eta_{L}^{-1}=(1-\theta) \frac{\beta}{\beta+(1-\beta)(L / H)^{\theta}} .
$$

As $0<H / L<\infty, \eta_{L}^{-1}$ is bounded by $0<\eta_{L}^{-1}<1-\theta$. Note that $\theta<1$ from (4). For the Cobb-Douglas case, the (inverse) labour demand elasticity is (app. 9.3), considering again $H$ as parametric for the union,

$$
\eta_{L}^{-1}=\beta
$$

This is a special case of (13) for $\theta=0$.

\subsection{The benefit system}

The unemployment benefit $b$ in (11) is an important determinant of the alternative income and therefore crucially determines how the unions set wages. In "Beveridge countries",

\footnotetext{
${ }^{14}$ When computing the demand elasticity $\eta_{L}$, we take $H$ as parametric: the union neglects the effects of its wage setting on employment of high-skilled but does take into account output effects through changes in employment of low-skilled.
} 
benefits are given by some fixed payment that is not related to the former earnings of an unemployed, ${ }^{15}$

$$
b_{B e v}=\bar{b} .
$$

In "Bismarck countries", the unemployment benefit is a fixed fraction of the previously earned wage. This system can be further differentiated into whether the fixed ratio is related to the net or the gross wage. We call these two sub-systems the net-Bismarck and grossBismarck system and specify them as

$$
\begin{gathered}
b_{n B}=\zeta\left[1-\tau_{L}\right] w_{L}, \\
b_{g B}=\zeta w_{L} .
\end{gathered}
$$

The wage setting curves we eventually get, when inserting (16), (17) and (15), respectively, into (12), are given by (app. 9.4)

$$
\begin{aligned}
(1-\zeta) u & =\eta_{L}^{-1}, \\
\left(1-\frac{\zeta}{1-\tau_{L}}\right) u & =\eta_{L}^{-1}, \\
\left(1-\frac{\bar{b}}{\left(1-\tau_{L}\right) w_{L}}\right) u & =\eta_{L}^{-1},
\end{aligned}
$$

for the net- and gross-Bismarck and the Beveridge system.

\section{Equilibrium analysis of EPRs}

We now analyse the unemployment equilibrium in the economy. Market equilibrium for highly skilled individuals is independent of the unemployment system. It follows from the demand function (2) and the supply function (6) or (7),

$$
F_{H}(H, L)=w_{H}^{s}\left(\tau_{H}, H\right) .
$$

\subsection{Net-Bismarck systems}

\subsubsection{The equilibrium system}

In addition to the equilibrium condition (21) on the high-skill market, an equilibrium description requires the low-skill labour-demand equation from (2) and the wage setting curve (18) for net-Bismarck countries. Reproducing all three equations here gives

$$
F_{H}(H, L)=w_{H}^{s}\left(\tau_{H}, H\right), \quad F_{L}(H, L)=w_{L}, \quad(1-\zeta) u=\eta_{L}^{-1} .
$$

\footnotetext{
${ }^{15}$ Following OECD (2002, tab. 2.2 and 2.3, summarized in app. 8), Canada, France, Germany, Italy, Spain and the USA have a predominantly net-Bismarck system, Austria, Japan and Portugal have a grossBismarck system and Australia, Ireland, New Zealand and the UK have a Beveridge system. Clearly, the complexity of the real-world benefit systems are not perfectly reflected by (15) to (17). We believe that our qualitative results on EPRs do not depend on this simplification. More quantitatively oriented future work needs to take the time structure of unemployment benefits into account.
} 
This system determines high-skill employment $H$, low-skill employment $L$ and the gross wage $w_{L}$ for low-skilled (noting that $u \equiv\left(L_{s}-L\right) / L_{s}$ by definition and $\eta_{L}$ is either a constant or a function of $H$ and $L$ - see (13) and (14)). These equilibrium quantities depend on the replacement rate $\zeta$ and the $\operatorname{tax} \tau_{H}$ for high-skill wages. When we study countries that do not have a net-Bismarck system, the third equation will be replaced by either (19) or (20).

We focus on labour taxation and the replacement rate in our policy analysis. When we do a comparative static analysis, totally differentiating gives after some steps (app. 10.1)

$$
\begin{aligned}
d H & =-\frac{\left(a_{2}+(1-\zeta) L_{s}^{-1}\right) \frac{L}{w_{L}} \epsilon_{H} a_{1}}{N_{n B}} d \tau_{H}-\frac{\epsilon_{H} \eta_{L}^{-1} \frac{L}{w_{H}} u}{N_{n B}} d \zeta, \\
d L & =-\frac{\epsilon_{H} a_{1} \frac{L}{w_{L}} a_{2} \frac{L}{H}}{N_{n B}} d \tau_{H}-\frac{u \frac{L}{w_{L}}\left(\epsilon_{H} \eta_{H}^{-1}+1\right)}{N_{n B}} d \zeta, \\
d w_{L} & =-\frac{\epsilon_{H} a_{1} \eta_{H}^{-1} \frac{w_{H}}{w_{L}}(1-\zeta) L_{s}^{-1}}{N_{n B}} d \tau_{H}+\frac{u \eta_{L}^{-1}}{N_{n B}} d \zeta,
\end{aligned}
$$

where the coefficients and the determinant $N_{n B}$ are given by

$$
\begin{aligned}
a_{1} & =\frac{\partial w_{H}^{s}}{\partial \tau_{H}} \frac{H}{w_{H}} \geq 0, \quad a_{2}=\frac{\partial \eta_{L}^{-1}}{\partial L} \gtreqless 0 \Leftrightarrow \theta \lesseqgtr 0, \\
\eta_{H}^{-1} & \equiv \frac{\partial w_{H}}{\partial H} \frac{H}{w_{H}}, \quad \epsilon_{H} \equiv \frac{\partial H}{\partial w_{H}} \frac{w_{H}}{H}, \\
N_{n B} & =\frac{L}{w_{L}}\left[a_{2}+(1-\zeta) L_{s}^{-1}\left(\epsilon_{H} \eta_{H}^{-1}+1\right)\right] .
\end{aligned}
$$

The abbreviation $a_{1}$ captures the effect of taxation on the supply of human capital, $a_{2}$ captures the change of (the inverse of) the $w_{L}$ wage elasticity of labour demand with respect to employment $L$. In analogy to $\eta_{L}^{-1}$ in $(10), \eta_{H}^{-1}$ is the inverse of the $w_{H}$ wage elasticity of human capital demand. The supply elasticity of human capital is denoted by $\epsilon_{H}$.

\begin{tabular}{llll} 
& $C D$-utility & $C D$-technology & general \\
\hline \hline$a_{1}$ & 0 & & $>0$ \\
$a_{2}$ & & 0 & $\gtrless 0$ for $\sigma \lessgtr 1$ \\
$\epsilon_{H}$ & 0 & & \\
\hline
\end{tabular}

Table 1 Parameter implications for special Cobb-Douglas cases

Table 1 shows special cases for the above system (22) (that hold for the gross-Bismarck and Beveridge system as well). When human capital supply is completely inelastic as in (8), then $a_{1}=\epsilon_{H}=0$ : labour income does not have any impact on human capital supply. When the technology is Cobb-Douglas, demand elasticities $\eta_{H}$ and $\eta_{L}$ are constant and $a_{2}=0$. Further, the determinant $N_{n B}$ is unambiguously positive.

Generally speaking, the sign of $a_{1}$ is non-negative (for upward-sloping human capital supply) and the sign of $a_{2}$ is positive if the elasticity of substitution $\sigma$ between factors of production is smaller than unity and negative for $\sigma>1$ (cf. app. 10.1). In general, the sign of $N_{n B}$ is ambiguous as well. When $a_{2}$ is not too negative, $N_{n B}$ is positive. ${ }^{16}$

\footnotetext{
${ }^{16}$ As equation (A.13) in the appendix shows, $a_{2}(\theta)$ is bounded from below. It intersects the horizontal $\theta$ line at $\theta=0$ and $\theta=1$. It approaches plus infinity for $\theta$ going to minus infinity. This shows that certain parameter restrictions would suffice to obtain a positive determinant.
} 


\subsubsection{Comparative static properties}

\begin{tabular}{lllll} 
& & unemployment & net wage $\left(1-\tau_{L}\right) w_{L}$ & benefits $b$ \\
\hline \hline$\tau_{H}$ & CDCD & 0 & 0 & 0 \\
& general & $+^{(1)}$ & - & - \\
\hline$\tau_{L}$ & CDCD/ general & 0 & - & - \\
\hline$\zeta$ & CDCD & + & + & + \\
& general & $+^{(1)}$ & $+^{(1)}$ & $+^{(1)}$ \\
\hline
\end{tabular}

Table 2 : General equilibrium effects of taxation and the replacement rate (1) An elasticity of substitution $\sigma$ between $H$ and $L$ smaller than one (i.e. $a_{2}>0$ ) is a sufficient condition

A summary of our results is in tab. 2. It covers the effects of the two policy instruments benefit replacement rate $\zeta$ and taxation $\tau_{L}$ and $\tau_{H}$ on unemployment, the net wage and benefit payments. We focus on two polar cases, the simplest one where both the technology and the utility function of high skilled are of the Cobb-Douglas type (CDCD) and the general case. The discussion below covers some intermediate cases as well.

These analytical results are illustrated in fig. 2 which plots low-skill labour on the horizontal and wages on the vertical axis. It shows the labour demand curve marked by $w_{L}$, the corresponding net-wage curve $\left(1-\tau_{L}\right) w_{L}$ and the benefit curve $\zeta\left[1-\tau_{L}\right] w_{L}$. The wage setting curve is the vertical line.

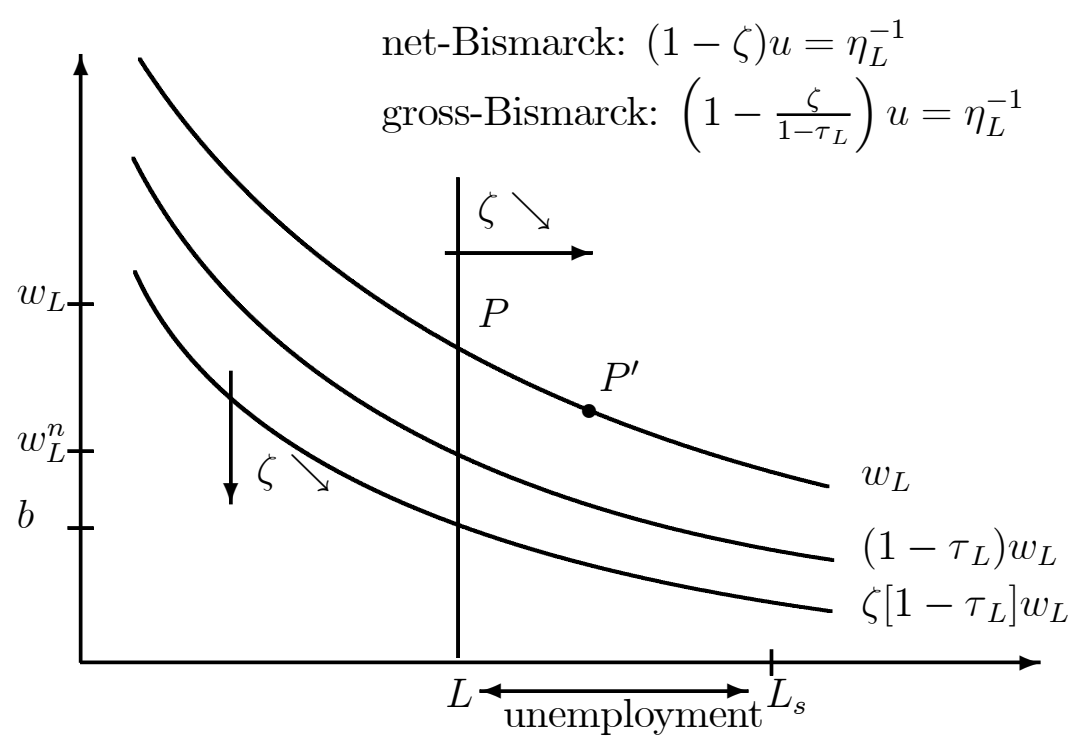

Figure 2 : The labour market for low-skilled in net-and gross-Bismarck systems

- The effects of taxation

When the technology is CD as in (5), $a_{2}=0$ and (24) shows that employment is not affected by taxation $\tau_{L}$ of low-skilled. Even when employment of high-skilled $H$ changes due to a variation in $\tau_{H}$, this only shifts the labour demand curve $w_{L}$ (and the other two 
curves below $w_{L}$ ) in fig. 2 but not the vertical wage setting curve. When human capital supply is constant as in (8), due to e.g. a Cobb-Douglas utility function, $a_{1}=\epsilon_{H}=0$ as well and taxation by (25) does not affect gross wages either. Hence, only net wages and benefit payments are affected by taxation in this CDCD case.

In more general cases for positive $a_{1}$ and $a_{2},(23)$ to (25) show that a higher $\operatorname{tax} \tau_{H}$ on high-skill wages decreases employment of low- (and high)-skill individuals and, due to fewer high-skilled, also the gross wage for low skilled. The net wage and benefit payments therefore also fall. Note that the negative employment effect for low skilled due to taxation $\tau_{H}$ results from the change in the inverse demand elasticity $\eta_{L}^{-1}$ in (13) which in turn is caused by a lower equilibrium human capital stock. ${ }^{17}$ When $a_{2}$ is negative (and the determinant $N_{n B}$ still positive), the employment effects for low-skilled change, but the effect on the gross and thereby net wage and benefits remain unchanged.

While the very weak link between taxation and low-skill employment is clearly due to the fact that individual labour supply is fix, it nevertheless highlights why the effect of taxation on employment in various countries differs considerably and why some authors find small effects of taxation on employment e.g. in Germany, a net-Bismarck country (Schneider et al., 2002).

\section{- Replacement rate}

The effects of the replacement rate are more straightforward from (23) to (25). As long as $a_{2} \geq 0$, a higher replacement rate $\zeta$ increases the gross wage, reduces employment of low-skilled and thereby also employment of high-skilled. The net wage increases and benefit payments increase because of the increase in the gross wage and directly through the increase of the replacement rate. With a negative $a_{2}$, results remain unchanged as long as the determinant remains positive. Figure 2 illustrates the case of a reduction of $\zeta$ and shows how the shift of the wage setting curve to the right increases employment at lower gross and net wages.

\subsubsection{How to preserve equality}

Given the results obtained so far, an employment increasing and equality-preserving tax reform seems straightforward. A lower replacement rate shifts the wage setting curve to the right and increases employment at lower gross wages. ${ }^{18}$ Net wages and unemployment benefits fall as well, requiring a reduction in labour taxation for low-skilled. If this reduction is only sufficiently strong (at the risk of ending up with negative taxation), more employment goes hand in hand with unchanged net wages or benefit payments. We define a reform to be

\footnotetext{
${ }^{17}$ Lower employment of $L$, however, moves $\eta_{L}^{-1}$ in the opposite direction as can be seen e.g. from (13). The overall effect on the position of the wage setting line in figure 2 remains a shift to the left as could be seen from totally differentiating (13).

${ }^{18}$ Lowering the replacement rate increases employment but not necessarily welfare. While this is wellunderstood in models where employment paths are uncertain and unemployment benefits play an insurance role, this is also true here: A social welfare function that aggregates utilities of the skilled and the unskilled workers plus the unemployed would require that in a social optimum marginal utilities of the unskilled must not be too high, i.e. their consumption levels, determined by the replacement rate, must not be too low.
} 
equality-preserving (EPR) if the net-wage does not decrease as a consequence of this reform,

$$
d\left[\left(1-\tau_{L}\right) w_{L}\right] \geq 0 .
$$

We will talk about an ambitious EPR when the reform keeps unemployment benefits unchanged or increases them,

$$
d b_{n B}=d\left[\zeta\left[1-\tau_{L}\right] w_{L}\right] \geq 0 .
$$

- Implementation of the EPR

The equality constraint (28) can best be illustrated by a iso-netwage curve depicted in the policy space $(\zeta, \tau)$. We assume here that labour taxes are flat, $\tau_{H}=\tau_{L} \equiv \tau$. They can therefore be reduced for human capital and labour only simultaneously. Section 5 treats the progressive tax case, where only $\tau_{L}$ is reduced. The iso-netwage curve draws combinations of $\zeta$ and $\tau$ where the net wage remains unchanged. By using (25) in (28) gives, assuming again a sufficiently large $a_{2}$, (cf. app. 10.1.2)

$$
d\left[(1-\tau) w_{L}\right] \geq 0 \Leftrightarrow d \tau \leq \frac{(1-\tau) u \eta_{L}^{-1}}{(1-\tau) \epsilon_{H} a_{1} \eta_{H}^{-1} \frac{w_{H}}{w_{L}}(1-\zeta) L_{s}^{-1}+w_{L} N_{n B}} d \zeta .
$$

As $N_{n B}>0$ for $a_{2}$ not too small, the slope of the iso-netwage curve is positive and we obtain the following figure. Note that the concept of these curves is identical to iso-cost or iso-output curves. While the latter shows by how much one factor of production needs to be increased at unchanged output when the other factor of production is marginally decreased, the iso-net wage curve shows by how much taxes need to be decreased at unchanged net wages when the replacement rate is marginally decreased.

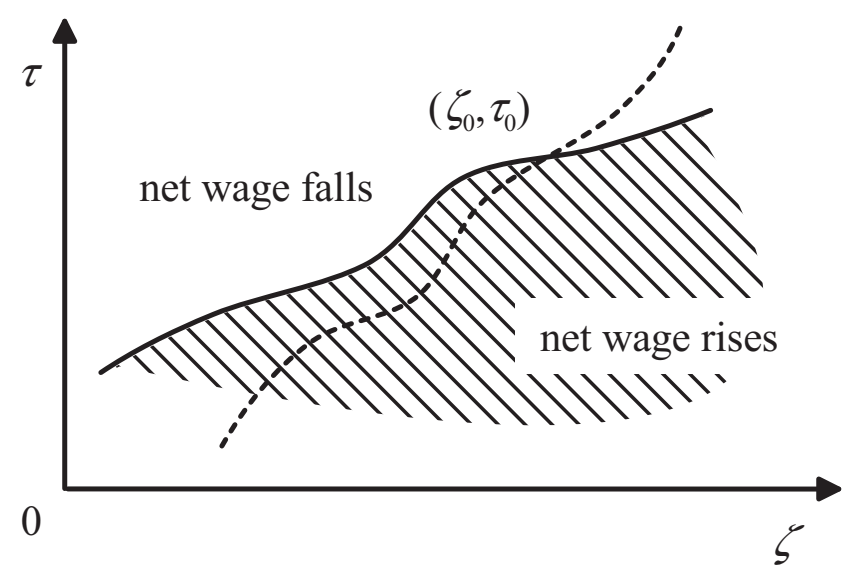

Figure 3 : Iso-netwage and iso-benefit curves in the policy space

Summarizing, any policy reform that starts from the current policy $\left(\zeta_{0}, \tau_{0}\right)$ lowers net wages when moving into the non-shaded area. Remaining on the iso-netwage curve keeps net wages constant and moving into the shaded area increases net wages. 
- Implementation of the ambitious EPR

A more ambitious EPR changes $\zeta$ and $\tau$ such that unemployment benefits (16) do not decrease. When we compute (29) with (25), we obtain (cf. app. 10.1.2)

$$
d b_{n B}=d\left[\zeta\left[1-\tau_{L}\right] w_{L}\right] \geq 0 \Leftrightarrow d \tau \leq \frac{[1-\tau] w_{L} N_{n B} / \zeta+[1-\tau] u \eta_{L}^{-1}}{w_{L} N_{n B}+[1-\tau] \epsilon_{H} a_{1} \eta_{H}^{-1} \frac{w_{H}}{w_{L}}(1-\zeta) L_{s}^{-1}} d \zeta .
$$

Compared to the iso-netwage curve (30), we have an additional term, $\left[1-\tau_{L}\right] w_{L} N_{n B} / \zeta$ in the numerator. As $N_{n B}$ is positive, however, the slope remains positive and, as the denominator is unchanged, the slope is larger. This is captured in the policy space in fig. 3 by the dashed iso-benfit line. This means that taxes need to fall faster given a certain decrease in the replacement rate if benefits are to be kept constant.

Looking again at fig. 2 illustrates why keeping net income of the unemployed constant is more ambitious than preserving constant net wages: A reduction in $\zeta$ not only shifts the wage setting curve to the right but also the benefit curve $\zeta\left[1-\tau_{L}\right] w_{L}$ down. Hence, a tax-reduction must be much stronger in order to keep $\zeta\left[1-\tau_{L}\right] w_{L}$ at its pre-reform level.

\subsection{Policy reforms in gross-Bismarck countries}

\subsubsection{The equilibrium system}

The only difference between the net- and the gross-Bismarck system is that the wage setting curve (19) is a function of the tax rate in the gross-Bismarck system, $\left(1-\frac{\zeta}{1-\tau_{L}}\right) u=\eta_{L}^{-1}$. When we compute the total differential of the equilibrium condition (21) on the high-skill market, the low-skill labour-demand equation from (2) and this equation, we obtain for labour $L$ and the gross wage $w_{L}$ (app. 10.2), ${ }^{19}$

$$
\begin{aligned}
N_{g B} d L & =-\frac{L}{w_{L}} a_{2} \frac{L}{H} a_{1} \epsilon_{H} d \tau_{H}-\frac{L}{w_{L}}\left(\eta_{H}^{-1} \epsilon_{H}+1\right)\left(a_{5} d \tau_{L}+\frac{u}{1-\tau_{L}} d \zeta\right), \\
N_{g B} d w_{L} & =\eta_{L}^{-1}\left[a_{5} d \tau_{L}+\frac{u}{1-\tau_{L}} d \zeta\right]-\frac{a_{1} \epsilon_{H} \eta_{L}^{-1}}{H}\left(1-\frac{\zeta}{1-\tau_{L}}\right) d \tau_{H} .
\end{aligned}
$$

\subsubsection{Comparative static properties}

Again, a summary of our results is provided in the following table. In the text, we do not explicitly discuss the effect of the replacement rate, as it is identical to the net-Bismarck case.

\footnotetext{
${ }^{19}$ We suppress here and in the Beveridge system the expression for $H$ as this is not central in our analysis. It is derived in the appendix.
} 


\begin{tabular}{lllll}
\hline & & unemployment & net wage & benefits $b$ \\
\hline \hline$\tau_{H}$ & CDCD & 0 & 0 & 0 \\
& general & + & - & - \\
\hline$\tau_{L}$ & CDCD/ general & + & $-{ }^{(2)}$ & + \\
\hline$\zeta$ & CDCD & + & + & + \\
& general & $+^{(1)}$ & $+^{(1)}$ & $+{ }^{(1)}$ \\
\hline
\end{tabular}

Table 3 : General equilibrium effects of taxation and the replacement rate: the grossBismarck case

(1) As in tab. 2, $a_{2}>0$ is a sufficient condition

(2) Direct taxation effect stronger than indirect gross wage effect

- The effects of taxation

In gross-Bismarck-type systems and in contrast to net-Bismarck countries, taxation of low-skill workers has an employment effect: unemployment increases unambiguously in the tax rate $\tau_{L}$ for a CD technology. The reason is the $a_{5}$ term or the fact that the wage setting curve moves to the left when the $\operatorname{tax} \tau_{L}$ increases. Economically speaking, this means that higher taxes reduce ceteris paribus the net wage. As, in contrast to net-Bismarck countries, the alternative income is unaffected by tax changes, unions compensate for this loss and move a part of this increasing wedge on to employers, the gross wage increases and employment falls.

The effect on the net wage is therefore ambiguous. On the one hand, the gross wage is higher, on the other hand, the share that is taxed away is higher as well. Assuming that the direct taxation effect is stronger than the indirect gross-wage-increasing effect, the net wage falls due to an increase in taxation. In contrast to this worse situation for workers, the unemployed benefit from higher taxes as their benefit payments (17) depend on the gross wage. As the latter increases due to higher taxes, benefit payments increase as well.

The tax on high-skilled has again no allocation effect as with CD utility, supply of human capital is fix and a tax is lump-sum. We therefore obtain the same results as in tab. 2 .

When we analyse tax effects in more general cases, assuming the same restrictions as in the above given analysis, i.e. $N_{g B}$ being positive and low-skilled and high-skilled labour have an elasticity of substitution lower than 1, i.e. $a_{2}>0$, (32) shows that higher taxes $\tau_{L}$ on labour still unambiguously lead to more unemployment. If taxes rates are flat, $\tau_{H}=\tau_{L}$, a higher tax leads to an even larger unemployment increase than in the case with invariant $H$.

With flat tax rates, the effect on the gross wage, however, is ambiguous now, as the $a_{1}$ term is positive. Obviously, due to the $a_{1}$ factor, the crucial aspect is played by human capital supply. With $a_{1}=0$, i.e. fixed $H$ supply, the gross wage and thereby benefit payments increase. When higher taxes imply lower supply of human capital, demand for workers shrinks which has a dampening effect on wage demands by unions and thereby implies moderation of gross wages. The effect on net wages should remain negative, provided again that the direct tax effect is stronger than the indirect effect. 


\subsubsection{How to preserve equality}

The formal condition for an EPR is identical to (28). The condition for an ambitious EPR differs from (29), as benefits are defined differently, $d b_{g B}=d\left[\zeta w_{L}\right] \geq 0$. Comparing tab. 2 and 3 shows that the mechanism in gross-Bismarck countries should be expected to be identical for the net wage. A lower tax increases the net wage, a lower replacement rate decreases it. At the same time, unemployment shrinks. A figure similar to fig. 3 (the solid line) would emerge.

Preserving equality from the perspective of the unemployed is more difficult, however. As tab. 3 shows, a higher tax $\tau_{L}$ on labour increases unemployment benefits but, at the same time, increases unemployment. This is a fundamental conflict of interest between the unemployed and society. Similarly (and for the same underlying reasons as discussed after tab. 3), a lower tax would lead to higher net wages but would also reduce unemployment benefits. There is a fundamental conflict of interest also between the unemployed and the employed.

\subsection{Policy reforms in Beveridge countries}

\subsubsection{The equilibrium system}

In Beveridge countries, the wage setting curve (20) is upward sloping and in this sense more similar to standard labour supply curves, as illustrated in fig. 4. The wage setting curve approaches $\eta_{L}^{-1}$ for $w_{L}$ going (ceteris paribus) to infinity.

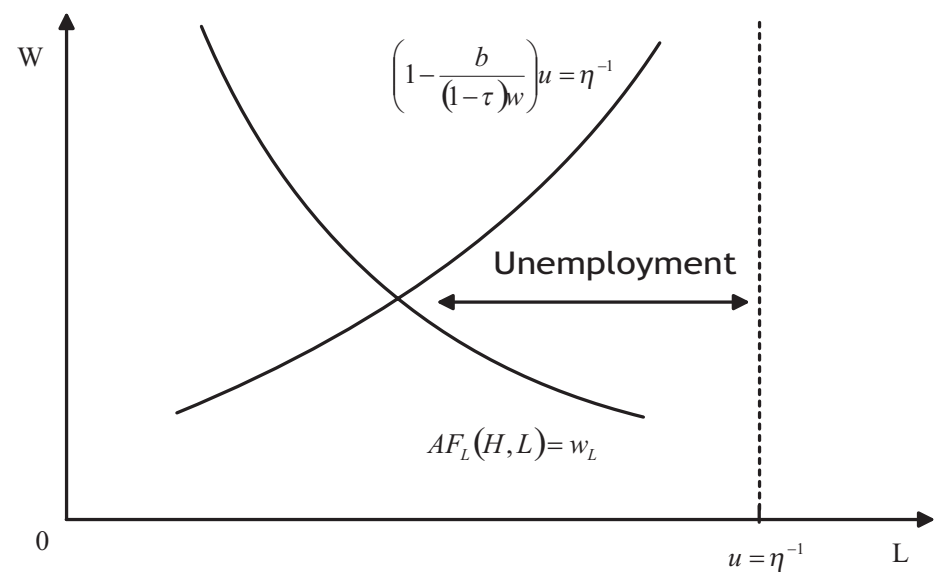

Figure 4 : The labour market for low-skilled in Beveridge systems

The general equilibrium in Beveridge countries is again given by (21) and (2), where we now add (20). Policy instruments in these countries are the tax rate and, in contrast to other countries, unemployment benefits $\bar{b}$ (and not the replacement rate $\zeta$ ). Computing 
total differentials gives (app. 10.3)

$$
\begin{aligned}
N_{B e v} d L= & -\left(\frac{L}{w_{L}} \frac{L}{H} a_{2}+\eta_{H}^{-1} \frac{w_{H}}{w_{L}} \frac{u-\eta_{L}^{-1}}{w_{L}}\right) a_{1} \epsilon_{H} \frac{H}{L} d \tau_{H} \\
& -\left(\epsilon_{H} \eta_{H}^{-1}+1\right) \frac{L}{w_{L}}\left(\frac{u-\eta_{L}^{-1}}{\bar{b}} d \bar{b}+\frac{u-\eta_{L}^{-1}}{\left(1-\tau_{L}\right)} d \tau_{L}\right) \\
N_{B e v} d w_{L}= & -\eta_{H}^{-1} \frac{w_{H}}{w_{L}} \eta_{L}^{-1} \frac{1}{u L^{S}} a_{1} \epsilon_{H} \frac{H}{L} d \tau_{H}+\eta_{L}^{-1}\left(\frac{u-\eta_{L}^{-1}}{\bar{b}} d \bar{b}+\frac{u-\eta_{L}^{-1}}{\left(1-\tau_{H L}\right)} d \tau_{L}\right),
\end{aligned}
$$

where the determinant is

$$
N_{B e v}=\eta_{L}^{-1} \frac{u-\eta_{L}^{-1}}{w_{L}}+\left(\epsilon_{H} \eta_{H}^{-1}+1\right) \frac{L}{w_{L}}\left(a_{2}+\eta_{L}^{-1} \frac{1}{u L^{S}}\right)-\epsilon_{H} \eta_{L}^{-1} \frac{L^{2}}{w_{H} H} a_{2} .
$$

\subsubsection{Comparative static properties}

Again, a summary of our results is provided in the following table.

\begin{tabular}{lllll}
\hline & & unemployment & net wage & benefits $b$ \\
\hline \hline$\tau_{H}$ & CDCD & 0 & 0 & 0 \\
& general & + & - & 0 \\
\hline$\tau_{L}$ & CDCD/ general & + & $-{ }^{(2)}$ & 0 \\
\hline$b$ & CDCD/ general & + & + & + \\
\hline
\end{tabular}

Table 4 : General equilibrium effects of taxation and unemployment benefits: the Beveridge case

(1) As in tab. 2 and 3, $a_{2}>0$ is a sufficient condition

(2) direct taxation effect stronger than indirect gross wage effect

The effect of policy on benefits in the last column is obvious, given that benefits are exogenous.

- Taxation

A tax on human capital in the CD utility case is again a lump-sum tax and has no allocative effect. In the more general case, a higher tax on human capital decreases supply of human capital and, as a consequence, the marginal productivity of labour. Unemployment therefore increases and the net wage of low-skilled goes down.

The effect of labour taxes is independent of the specification of technology and preferences. Unemployment unambiguously increases in the tax and the net wage falls. This is due to the fact that the union will increase its wage demands in both situations.

- Benefits

As (34) shows, higher benefits increase unemployment unambiguously in both CD as well as general cases. From (35), the gross and thereby also the net-wage increases in benefits. 


\subsubsection{How to preserve equality}

The EPR is possible and works as before. Unemployment benefits are reduced to fight unemployment which reduces the net wage. Reducing labour taxes $\tau_{L}$ reduces unemployment further and increases the net wage. The ambitious EPR is straightforward: By definition of the ambitious EPR, unemployment benefits $\bar{b}$ must remain constant. The only policy instrument that is then left to reduce unemployment is the tax rate $\tau$. As lower taxes imply lower unemployment, a reduction in unemployment without hurting the unemployed requires lower taxes.

\section{Towards self-financing reforms}

The previous analysis provided suggestions for policy reforms that reduce unemployment without reducing net income of workers or the unemployed. We did not analyse the effects of a joint change in the replacement rate and taxation on the government's budget balance. Needless to say that this effect is of crucial importance for the political feasibility.

Our proposals are constructed such that they have the potential to be self-financing: Think, for illustration purposes, of a net-Bismarck country. An EPR (and an ambitious EPR) consists of two components: a reduction in the replacement rate and a reduction in labour taxation. The reduction in labour taxation decreases tax revenue of the government while a reduction in the replacement rate reduces government expenditure. The first effect is a negative one for the government budget, the second one is positive. In principle, they could cancel out. ${ }^{20}$ Clearly, only a reform that reduces unemployment, that does not reduce net-income of any agent and that does not increase the government's budget deficit is a Pareto-improving reform.

\subsection{Net-Bismarck conditions}

Before we give conditions under which our EPRs are self-financing in net-Bismarck countries, we illustrate the approach. It is in its structure identical for all benefit systems.

\subsubsection{The government budget}

Policy reforms are self-financing when the government budget does not deteriorate due to the reform. To find out whether this is the case, we start from the government budget constraint, expressed for a net-Bismarck country as

$$
B=\tau Y-b_{n B} U=\tau Y-\zeta w_{L}^{n} U
$$

The number of unemployed is denoted by $U$, the net wage by $w_{L}^{n}$ and taxes are flat, $\tau_{H}=$ $\tau_{L} \equiv \tau$, an assumption to be relaxed again in the next section.

\footnotetext{
${ }^{20}$ Note that we do assume (and even show for one example in app. 11.1.2) that we are on the "correct side" of the Laffer curve, i.e. $d(\tau Y) / d \tau>0$. While lower taxation might lead to more employment, we do not assume that this increase in employment and the implied increase in tax income would overcompensate the losses due to a lower tax rate. It is the decrease in the replacement rate and the induced effect of less spending (leaving more employment apart) that might compensate reduced tax income.
} 
- The EPR condition

When we want to perform an EPR and assume that human capital supply is inelastic, i.e. the high-skilled have a CD utility function, the equality constraint (28) imposes a certain relationship between a change in the replacement rate and the tax rate,

$$
\begin{gathered}
d\left[(1-\tau) w_{L}\right]=0 \Leftrightarrow(1-\tau) d w_{L}=w_{L} d \tau \\
\Leftrightarrow(1-\tau) \frac{w_{L}}{\zeta} \eta_{\zeta} d \zeta=w_{L} d \tau \Leftrightarrow d \tau=\frac{1-\tau}{\zeta} \eta_{\zeta} d \zeta,
\end{gathered}
$$

where

$$
\eta_{\zeta} \equiv \frac{\partial w^{L}}{\partial \zeta} \frac{\zeta}{w_{L}}
$$

When differentiating, we used the fact that in the net-Bismarck case with equations (2) and (18), the gross wage is only a function of $\zeta$ and not a function of the tax rate as long as human capital supply is fixed. The equality constraint simply says that when the replacement rate is decreased, the tax must be decreased as well by the amount $(1-\tau) \zeta^{-1} \eta_{\zeta}>0$ to keep the net wage constant. An EPR is then self-financing when the differential of the government budget, taking this required decrease in taxation, captured by constraint (37), into account, is non-negative.

Observing that $d w_{L}^{n}=0$, the differential of the budget constraint is

$$
\begin{aligned}
d B & =Y d \tau+\tau d Y-w_{L}^{n} U d \zeta-\zeta w_{L}^{n} d U \\
& =Y d \tau+\tau \frac{\partial Y}{\partial \zeta} d \zeta-w_{L}^{n} U d \zeta-\zeta w_{L}^{n} \frac{\partial U}{\partial \zeta} d \zeta
\end{aligned}
$$

where we use, similar to above, that in the net-Bismarck case output through labour and through the gross wage $w_{L}$ is only a function of $\zeta$ as long as human capital supply is fixed. Inserting the equality constraint (37) gives

$$
\begin{aligned}
& d B=\left(Y \frac{1-\tau}{\zeta} \eta_{\zeta}+\tau \frac{\partial Y}{\partial \zeta}-w_{L}^{n} U-\zeta w_{L}^{n} \frac{\partial U}{\partial \zeta}\right) d \zeta \\
& =\left(Y \frac{1-\tau}{\zeta} \eta_{\zeta}+\tau \frac{\partial Y}{\partial \zeta}-w_{L}^{n} U\left[1+\frac{\partial U}{\partial \zeta} \frac{\zeta}{U}\right]\right) d \zeta
\end{aligned}
$$

The effect of a policy reform that changes $\zeta$ and $\tau$ on the budget is now a function of the change in $\zeta$ only. The change in $\tau$ was replaced by the relationship between $d \tau$ and $d \zeta$, imposed by the equality constraint (37). An EPR is self-financing when $d B \geq 0$ as a result of $d \zeta<0$. This requires the expression in brackets (.) to be negative.

This equation shows various channels through which a policy reform acts. The first two expressions show the change in income of the government, the last two expressions show changes in expenditure. An increase (decrease) in the replacement rate increases (decreases) expenditure because more (less) is paid per unemployed person (given a constant net wage), the $w_{L}^{n} U$ term, and because the gross wage increases (decreases), the last term. An increase (decrease) in the replacement rate also decreases (increases) output and thereby reduces (increases) tax income, the second term. Finally, given our equality constraint (37), a higher 
(lower) replacement rate requires higher (lower) taxation and therefore leads to an increase (decrease) in tax income, the first term. We therefore have three negative terms and one positive term within the brackets.

- The ambitious EPR condition

If we want to perform an ambitious EPR, we need to replace the iso-net wage constraint (37) by the iso-benefit constraint $(29), d b_{n B} \geq 0$. The policy constraint implied by an invariant benefit is

$$
d b_{n B} \geq 0 \Leftrightarrow[1-\tau] w_{L} d \zeta-\zeta w_{L} d \tau+\zeta[1-\tau] \frac{\partial w_{L}}{\partial \zeta} d \zeta \geq 0
$$

where again, as in (37), the differential of $w_{L}$ used the fact that in the net-Bismarck case and with inelastic $H$ the gross wage is only a function of $\zeta$. Instead of (37), we now have

$$
[1-\tau]\left(w_{L}+\zeta \frac{\partial w_{L}}{\partial \zeta}\right) d \zeta=\zeta w_{L} d \tau \Leftrightarrow[1-\tau]\left(1+\eta_{\zeta}\right) d \zeta=\zeta d \tau
$$

The differential of the budget (36) now reads instead of (39) $d B=\tau d Y+Y d \tau-b_{n B} d U$ as $b_{n B}$ is constant by policy design. The subsequent steps remain unchanged and we obtain

$$
d B=Y d \tau+\tau \frac{\partial Y}{\partial L} \frac{\partial L}{\partial w_{L}} \frac{\partial w_{L}}{\partial \zeta} d \zeta-b_{n B} \frac{\partial U}{\partial L} \frac{\partial L}{\partial w_{L}} \frac{\partial w_{L}}{\partial \zeta} d \zeta
$$

This means we only "lose" the term $-w_{L}^{n} U d \zeta$. The economics behind this effect is that the governmental budget cannot take advantage of lower payments to the unemployment after the reform as was the case in the previously analysed case. But this in turn implies that c.p. the condition for the funded, ambitious EPR to be successful becomes harder to fulfil.

Plugging in the iso-benefit condition (41) into the iso-budget relation gives

$$
d B=\left(Y \frac{1-\tau}{\zeta}\left(1+\eta_{\zeta}\right)+\tau \frac{\partial Y}{\partial \zeta}-\zeta w_{L}^{n} \frac{\partial U}{\partial \zeta}\right) d \zeta
$$

This equation nicely contrasts the condition for the funded reform to hold in the case in which only the net wage has been kept constant. Firstly, there is an additional term in the part which depicts the revenue decline due to the decrease in the tax rate. This implies that the tax rate has to decrease by a larger amount to keep the unemployment income constant than it was the case in the previous section. Secondly, the expenditure saving effect (depicted by the second term) is smaller than before. This is because only the employment decrease leads to less governmental expenditure not the decrease of the unemployment payment as before (by definition). Again, an ambitious EPR is self-financing when $d B \geq 0$ as a result of $d \zeta<0$.

\subsubsection{The EPR}

Let us now analyse the EPR condition (40) in more detail for the CDCD case $^{21}$. We derive in app. 11.1.1 a sufficient (and necessary) condition for the tax rate $\tau$ and the parameter $\beta$

\footnotetext{
${ }^{21}$ Here and in what follows we restrict attention to the CDCD case where both the utility function of high-skilled and the technology are of the Cobb-Douglas type.
} 
from the CD technology (5) under which an EPR is self-financing. This condition guarantees that the derivatives in (40) are negative, i.e. a decrease in $\zeta$ (which decreases unemployment) - at constant net wages given the contemporaneous tax cut - increases the budget balance. The condition reads

$$
\tau>2-\beta^{-1} .
$$

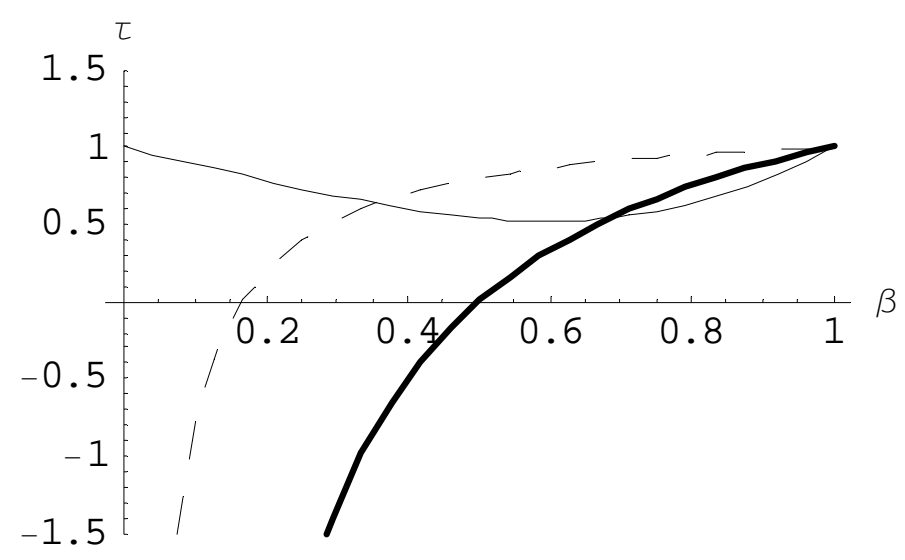

Figure 5 Minimum tax rates for self-financing

Fig. 5 plots (43) as the thick line in its equality version, i.e. $\tau=2-\beta^{-1}$. (We will refer to the other lines in what follows.) Parameter combinations which lie on or above the thick line imply a self-financing EPR: The higher the tax rate and the lower $\beta$, the more likely self-financing becomes. Note that this condition is independent of $\zeta$ and thereby independent of the unemployment in a certain country. ${ }^{22}$

This figure also shows that wage subsidies could also be self-financing: if we think of lowincome groups that do not pay taxes and whose social-security contributions are also very low, one might have to pay subsidies in order to preserve their pre-reform net income. If $\beta$ is, say, .2 , the tax on labour could become negative and the reform would still be self-financing.

Is this condition bounded to be fulfilled in practice? The parameter $\beta$ captures in our CDCD case both the inverse of the (absolute) demand elasticity of labour, $\eta_{L}^{-1}=\beta$ from (14), and the share of labour income going to the high-skilled (5). The demand elasticity $\eta_{L}$ is usually estimated to lie in the long-run at between .4 and .7 (Hamermesh, 1993, p. 272), maybe between .15 and .75 (Hamermesh, 1993, p. 135). This would require in our specification a $\beta$ larger than unity which, given the production function (5) makes no sense. We will therefore take the share of high-skill income in total labour income as interpretational background for $\beta$. This share should be smaller than .5 and the condition would then always be satisfied. Given the ambiguity on which interpretation to give for $\beta$, we do not put to much emphasis on this result at this stage.

\footnotetext{
${ }^{22}$ This follows from the fact that the rate of unemployment in net-Bismarck systems depends only on $\zeta$.
} 


\subsubsection{The ambitious EPR}

The condition (42) for the ambitious EPR to hold reads for the CDCD case (app. 11.1.3)

$$
\tau>1-\frac{(1-\beta) \beta \zeta}{(1-\beta)(1-\zeta)^{2}+\beta^{2} \zeta^{2}} .
$$

The thin line in Figure 5 plots this condition for $\zeta=0.4$. This value is a rough guess of the average replacement rate in net-Bismarck countries from tab. 5 and with a tax rate of around .2 for the unemployed. What can be seen is that the condition for the ambitious $\mathrm{EPR}$ is, for most of the parameter range of $\beta$, more restrictive than the condition for the EPR. What is worse, the curve never falls below .5. It seems therefore highly implausible that an ambiguous self-financing EPR is possible.

\subsection{Gross-Bismarck conditions}

Let us now derive conditions under which EPRs are self-financing when we look at grossBismarck countries. The approach in this case is the same as in the net-Bismarck situation. When we assume CDCD economies again, we can obtain a condition for the EPR to be self-financing that corresponds to (43). It reads (app. 11.2.2)

$$
\tau>2(1-\zeta)-\beta^{-1}(1-2 \zeta)
$$

This is similar to the net-Bismarck case. The terms $1-\zeta$ and $1-2 \zeta$ shift the curve where the EPR is just self-financing upwards as long as $\beta<1$. Its precise position is plotted in fig. 5 for the same $\zeta$ as above. Hence, compared to the net-Bismarck system, self-financing of EPRs becomes even more difficult.

The ambitious EPR is, in gross-Bismarck countries, not so ambitious after all. As tab. 3 shows, a compensation of the unemployed for lower benefits due to a lower replacement rate $\zeta$ requires higher (and not lower) taxes: Higher taxes yield higher gross wages which is the second component (in addition to $\zeta$ ) in expression (17) for unemployment benefits. As a consequence, such a policy would always be self-financing as lower replacement rates and higher taxes both imply more income. As the discussion above has shown, however, such a policy is strongly against the interest of workers. What is more, as (32) shows, the effects of such a policy on employment are not clear either. An ambitious EPR does therefore not appear to be a valid policy option.

\subsection{Beveridge conditions}

In this section we will analyse the conditions under which an EPR and an ambitious EPR exist for the institutional setting of a fixed unemployment benefit (i.e. a benefit that is not related to the wage). This type of setting is very common in the Anglo-Saxon world (but not in the USA).

\subsubsection{The EPR}

As tab. 4 has shown, compensating workers for net-wage losses due to lower benefits is again possible, as in gross- and net-Bismarck systems, by reducing taxes on labour. Computing 
simple conditions as in (43) or (45) with respect to self-financing is not possible, however, as the unemployment rate (20) in the UK, once the dependence of the wage in (20) on the unemployment rate is taken into account, can only be expressed as an implicit function of $\tau$ and $\bar{b}$. Inserting the gross wage, which is $w_{L}=(1-\beta)\left(H / L_{s}\right)^{\beta}(1-u)^{-\beta}$ from (A.21), into (20) shows this, $\left(1-\frac{(1-u)^{\beta} \bar{b}}{(1-\tau)(1-\beta)\left(H / L_{s}\right)^{\beta}}\right) u=\beta$. We therefore need to solve the condition under which self-financing is just possible numerically (see app. 11.3.1) and obtain the following figure.

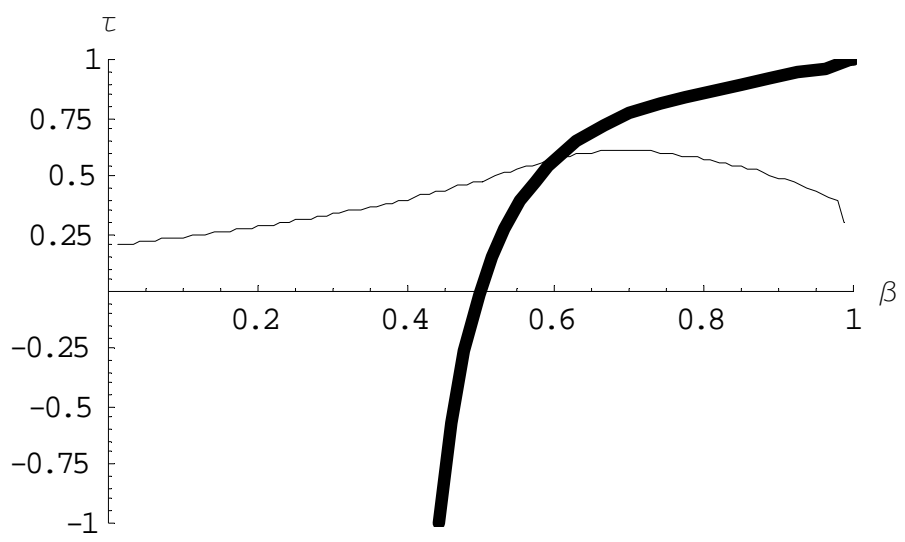

Figure 6 Minimum tax rates for self-financing in Beveridge countries

We see the fat line showing tax rates $\tau$ above which an EPR is self-financing. If the share $\beta$ of high-skill income in total income from (5) is low a self-financing EPR is possible. This is qualitatively the same result as with net-Bismark countries as shown in fig. 5 .

\subsubsection{The ambitious EPR}

Given the simple way to implement an ambitious EPR in Beveridge systems (keep benefits unchanged and cut taxes), it seems obvious that such a reform can never be self-financing. Assuming that an economy is on the left of the Laffer curve, any decrease implies lower government income. At the same time, however, the government saves on unemployment expenditure as the number of the unemployed decreases. Could the second effect be stronger?

Answering this question again numerically, we find a condition that also reminds of the conditions in net-Bismark countries. The thin line in fig. 6 has the same qualitative properties as the thin line in fig. 5. Again, it requires higher tax rates for the ambitious EPR to be self-financing.

\section{Self-financing reforms}

The analysis so far confined itself to identical tax rates for all labour groups. We found that self-financing EPRs and self-financing ambitious EPRs are possible only for certain parameter constellations; in gross-Beveridge systems, an ambitious EPR is not possible at all. This 
section therefore studies a more sophisticated policy change and investigates the conditions under which self-financing is possible when tax cuts are made only for low-income groups. We focus on net-Bismarck systems as countries in Europe with the highest unemployment problems have these systems.

\subsection{Through progressive taxation}

One reason for potentially harmful effects on the government budget is the fact that labour taxation decreases for all groups of labour, whether skilled or unskilled, whether employed or unemployed. If the objective is to create employment at unchanged net wages or benefits, it would be enough to reduce labour taxation only for the unskilled. We will therefore analyse in this subsection the effect of a more progressive tax system.

There are many ways how progressivity of a tax system can be modelled. We use a very simple one where we reduce the tax rate for low-skilled and keep the tax rate for the high-skilled unchanged. ${ }^{23}$ More progression therefore does not mean "taxing the rich" and "giving it to the poor". The highly-skilled have the same tax rates before and after the reform. We will see, however, that high-skilled nevertheless benefit from the reform through more employment of the low-skilled.

\subsubsection{The EPR}

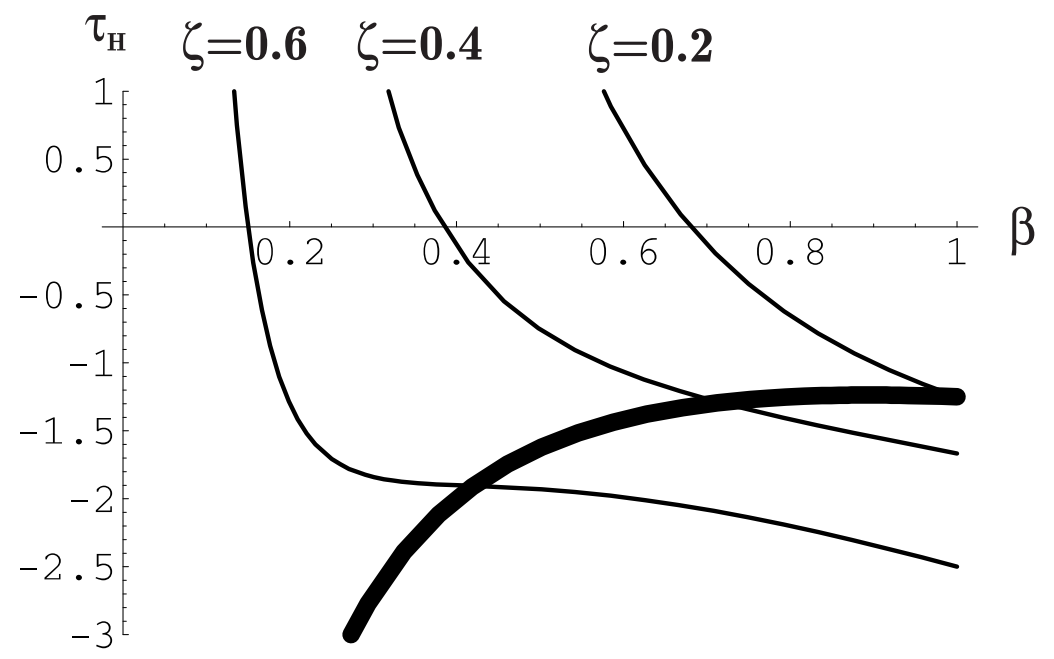

Figure 7 Self-financing conditions for an EPR and for ambitious EPRs

In deriving a condition for a self-financing EPR, we follow the steps as in the previous analysis. The budget is now expressed by $B=\tau_{L} w_{L} L+\tau_{H} w_{H} H-\zeta w_{L}^{n} U$, where $\tau_{H}$ is constant. After various steps (cf. app. 12.1), we obtain as a condition, comparable to (43) above,

$$
\tau_{H}>1-u-\beta^{-1}
$$

\footnotetext{
${ }^{23}$ While this is in a modelling sense simply a skill-specific linear tax schedule, it is intended to reflect rising marginal tax rates in a world with many skill groups.
} 
As $\beta$ is smaller than unity, this condition is always satisfied. Illustrating it as the thick line for $\zeta=.2$ gives fig. 7. A reduction in the replacement rate can always be accompanied by a reduction in taxation for low-skilled such that net wages remain unchanged and the government deficit is not increased. A self-financing EPR is possible with more progressive taxation.

\subsubsection{The ambitious EPR}

Let us now analyse whether keeping net benefits constant can more easily be achieved as well when only taxes for low-skilled are reduced. We obtain as our new condition (app. 12.1)

$$
\tau_{H}>(1-u)\left(\left[1-\tau_{L}\right](1-\zeta) \frac{1}{u \zeta \beta}+1\right)-\beta^{-1}\left(\tau_{L}+\zeta\left(1-\tau_{L}\right)\right) .
$$

This condition is plotted in fig. 7 three times as the thin lines with a pre-reform tax for labour of $\tau_{L}=.4$. The line to the left is obtained for $\zeta=.6$, the one in the middle has $\zeta=.4$ and the one to the right has a $\zeta$ of .2. We see here again that a self-financing ambitious EPR is indeed more difficult to implement than an EPR, as it requires a larger pre-reform tax than a self-financing EPR. For shares $\beta$ of high-skill income in total labour income that are low, $\tau_{H}$ needs to be sufficiently large for self-financing to work. If, however, $\beta$ is larger than .5 , self-financing ambitious EPRs are possible as well. Put differently, the net-Bismarck system is more "distribution-friendly" than the other systems. Efficiency gains obtained through lower replacement rates can be distributed by using the existing tax system among all economic agents such that policy reforms do not only create efficiency gains but are even Pareto improving.

\subsection{Reform of systems}

The results on progressive taxation shows that the net-Bismarck system is relatively "distributionfriendly". We have seen previously that the gross-Bismarck system excludes by design an ambitious EPR. Obviously, benefit systems differ in their implicit distributional properties.

We therefore ask whether a country that wants to reduce unemployment without increasing inequality could first adopt the net-Bismarck system and then perform the desired reforms. If one wants to convince a government (having, say, a gross-Bismarck system) to adopt a net-Bismarck system, one should make sure that crucial properties of the economy adopting the new system do not change: First, the unemployment rate should not change. The unemployment rate $u^{G}$ is determined in a gross-Bismarck country by (19), $\left(1-\frac{\zeta^{G}}{1-\tau_{L}^{G}}\right) u^{G}=\eta_{L}^{-1}$. After adoption of the new system, we want the unemployment rate to remain unchanged, i.e. $\left(1-\zeta_{\text {new }}^{G}\right) u^{G}=\eta_{L}^{-1}$. This requires an increase in the replacement rate to adjust for taxation, $\zeta_{\text {new }}^{G}=\zeta^{G} /\left(1-\tau_{L}^{G}\right)$. As the tax rate $\tau_{L}^{G}$ does not change, government income does not change. Unemployment payments do not change either, as instead of paying $\zeta^{G} w$ to each unemployed, the government pays $\zeta_{\text {new }}^{G}\left(1-\tau_{L}^{G}\right) w$ which, by construction, is the same. Hence, replacing one system by another is straightforward without changing equilibrium properties of the economy. As a simple adoption of the net-Bismarck 
system by Beveridge countries an vice versa is possible as well, Pareto-improving unemployment policies work best when first adopting the most distribution friendly system and then implementing the right reform measures.

\subsection{Are incentives right?}

The purpose of our policy proposal is to decrease unemployment without changing the absolute situation of the low-skilled or the unemployed, respectively. Thus, we implement a "policy vector" $\left(\zeta, \tau_{L}\right)$ that either leaves the low-skill wage constant or even increases it. One could be tempted to argue that this gives rise to a long-run incentive problem in the economy. If the policy proposal decreases the net high-skill wage at invariant low-skill wages, the incentive to invest into skill-formation will decline. This would distort the long-run evolution of the economy in an unfavourable way. Although these dynamic considerations are not modelled in this paper, we analyse whether our policy could generate these disincentive effects. We therefore analyse the effects of our policy proposal on the relative net wage $\left(1-\tau_{H}\right) w_{H} /\left[\left(1-\tau_{L}\right) w_{L}\right]$.

In the EPR case, the net wage $\left(1-\tau_{L}\right) w_{L}$ is constant by construction and the tax on $w_{H}$ is also held constant in the tax progression case. The gross wage for high-skilled $w_{H}$ goes up as higher employment increases the marginal productivity of human capital. Hence, in this case, incentives to invest in human capital are even improving.

In the ambitious EPR case, relative wages can be expressed by $\zeta\left(1-\tau_{H}\right) w_{H} /\left[\zeta\left(1-\tau_{L}\right) w_{L}\right]$. A tax-progression policy reform keeps the denominator constant and changes $\zeta$ and $w_{H}$. The change in the relative net wage is therefore

$$
d \frac{\zeta\left(1-\tau_{H}\right) w_{H}}{\zeta\left(1-\tau_{L}\right) w_{L}}=\frac{1-\tau_{H}}{\zeta\left(1-\tau_{L}\right) w_{L}}\left(\zeta d w_{H}+w_{H} d \zeta\right) \geq 0 \Leftrightarrow \frac{\zeta}{w_{H}} \frac{d w_{H}}{d \zeta} \geq-1 .
$$

Apparently, an ambitious EPR does not decrease the net wage ratio if the elasticity of gross wages for human capital with respect to the replacement rate is larger than minus one. Intuitively, one would expect this elasticity to be negative: A higher replacement rate implies lower employment of low-skilled which decreases marginal productivity of high-skilled. The question is, how strong the reaction of high-skill wages to low-skill unemployment is.

Let us now look again at the CDCD case. We analyse the net-Bismarck system as it has turned out above that it is the most appropriate for Pareto-improving unemployment reductions. From app. 12.2, the elasticity is

$$
\frac{\zeta}{w_{H}} \frac{d w_{H}}{d \zeta}=-(1-\beta) \frac{\zeta}{1-\zeta} \frac{u}{1-u}
$$

As the unemployment rate is below $50 \%, u /(1-u)<1$. The replacement rate in netBismarck countries is around .5 and therefore $\zeta /(1-\zeta) \approx 1$. As $1-\beta<1$ as well, we conclude that one can reasonably expect that $\frac{\zeta}{w_{H}} \frac{d w_{H}}{d \zeta}>-1$ such that even the ambitious EPR keeps incentives for human capital investment in place. 


\section{Conclusion}

Many continental European countries are still fighting with high unemployment rates. Some countries succeeded in the eighties or nineties to considerably reduce unemployment. Those countries who were successful experienced an increase in gross wage inequality over the period where unemployment dropped. This paper asks whether a reduction in unemployment caused by a reduction in the replacement rate or unemployment benefits, implying higher gross-wage inequality, can be accompanied by changes in the tax system such that a reduction of net income of the low-income groups can be avoided.

Two versions of constant low-income are considered: On the one hand, we ask under which conditions an equality preserving reform (EPR) can be implemented, i.e. a policy reform that reduces unemployment without reducing the net-wage of low-skill workers. On the other hand, we analyse ambitious EPRs, i.e. policy reforms that also reduce unemployment but keep net-income of the unemployed constant. We show that EPRs are possible in all institutional setups considered here (net- and gross-Bismarck and Beveridge systems). Ambitious EPRs, however, can be implemented only in net-Bismarck and Beveridge systems. In this sense, the gross-Bismarck system is not "distribution friendly".

When analyzing the budgetary requirements for the government, we find that EPRs are self-financing for some parameter constellations. Ambitious EPRs, however, are hardly self-financing. The budgetary cost implied by the reduction in labour taxes required to keep income of the unemployed at their pre-reform level are just too high and can not be compensated by lower expenditure due to the reduced number of unemployed.

We therefore analyse the effect of reducing tax rates only for low-income workers. This implies a more progressive tax and social security contributions system and makes EPRs under net-Bismarck systems always self-financing. Ambitious EPRs also become much more likely to be self-financing. We further show that it is possible for countries to switch from one benefit system to another relatively easily without affecting the unemployment rate and public budget balances. This would allow countries to first adopt the most distribution friendly benefit system and then perform reforms that reduce unemployment. Finally, incentives to become skilled are not distorted by more progressive tax systems - the ratio of net wages should actually increase when policies are implemented that reduce unemployment and keep net income of the unemployed constant. Efficiency gains through lower unemployment can therefore be distributed within existing system such that everybody benefits from these efficiency gains.

One can think of various extensions of our approach. While we did show that selffinancing ambitious EPRs and EPRs are possible in principle, more complex models than the ones we used are required before reliable policy recommendations can be made. One would need models that allow for serious calibration (as e.g. Sørensen, 1997) and detailed comparison of e.g. real world unemployment rates and those predicted by the model. Other forms of unemployment than trade union unemployment would be required for countries where trade union density is not so high.

Modelling the duration of unemployment would be very interesting as well (for a recent excellent overview and analysis, see Ljungqvist and Sargent, 2002). Given that the replacement rate is not always a highly significant determinant of unemployment in empirical work (see footnote 5), the joint effect of the length of unemployment payments and of the re- 
placement rate on unemployment could be better understood. From a policy perspective, a dynamic approach would allow to jointly analyse negative income tax features and the measures we propose.

These more elaborate models could then be used to see quantitatively by how much taxes must fall in order to keep net income of various groups constant and by how much and how fast (in a dynamic setup) the contemporaneous decrease in the replacement rate would affect unemployment. One could also investigate how endogenous labour supply decisions of unskilled workers or the effect of additional taxes help to fulfill the self-financing objective. If there was a, say, value-added tax in our model, less unemployment would cause higher tax income directly because of higher employment (this channel is included in our analysis) but also indirectly because of higher consumption and the implied value-added taxes. This should generally allow to design self-financing reforms more easily.

\section{References}

Belot, M., and J. C. van Ours (2004): "Does the recent success of some OECD countries in lowering their unemployment rates lie in the clever design of their labor market reforms?," Oxford Economic Papers, 56, 621-642.

Blanchard, O., and J. Wolfers (2000): "The Role of Shocks And Institutions In the Rise Of European Unemployment: The Aggregate Evidence," Economic Journal, 110, C1-C33.

Bovenberg, A. L. (2005): "Tax policy and labour market performance," In J. Agell and P. Sørensen (eds.), Tax Policy and Labour Market Performance, CESifo and MIT Press, Cambridge, Mass.

Cahuc, P., and E. Lehmann (2000): "Should unemployment benefits decrease with the unemployment spell?," Journal of Public Economics, 77, 135-153.

Cahuc, P., and A. Zylberberg (2004): Labor Economics. MIT Press.

Clark, T., and A. Leicester (2004): "Inequality and Two Decades of British Tax and Benefit Reforms," Fiscal Studies, 25, 129-158.

EEAG (2002): "Welfare to Work," Report on the European Economy 2002 by the European Economic Advisory Group, www.cesifo.de: Munich, ch. 6, $71-86$.

Friedman, M. (1962): Capitalism and Freedom. Chicago: University of Chicago Press.

Hamermesh, D. S. (1993): Labor Demand. Princeton University Press.

Hanushek, E. A., C. K. Y. Leung, and K. Yilmaz (2003): "Redistribution through education and other transfer mechanisms," Journal of Monetary Economics, 50(8), 1719-1750, pdf.

Hoon, H. T., and E. S. Phelps (2003): "Low-wage employment subsidies in a labor-turnover model of the "natural rate"," In Phelps E. S. (ed.), Designing Inclusion - Tools to Raise Low-end Pay and Employment in Private Enterprise, ch. 1. Cambridge University Press. 
Jerger, J., and A. Spermann (1997): "Promoting Low-Wage Employment: The Case for a Targeted Negative Income Tax," Jahrbuch für Wirtschaftswissenschaften Review of Economics, 48, 269-287.

Johnson, P., and S. Webb (1993): "Explaining the Growth in UK Income Inequality: 1979 1988," Economic Journal, 103, 429-435.

Kaas, L., and L. von Thadden (2004): "Budgetary Policy and Unemployment Dynamics in an OLG Model with Collective Bargaining," Economic Journal, 114, 867-889.

Kahn, L. (2000): "Wage Inequality, Collective Bargaining And Relative Employment from 1985 to 1994: Evidence from fifteen OECD Countries," Review of Economics and Statistics, 82, 564-579.

Kleven, H. J., and P. B. Sørensen (2004): "Labour Tax Reform, the Good Jobs and the Bad Jobs," Scandinavian Journal of Economics, 106, 45-64.

Koeniger, W., M. Leonardi, and L. Nunziata (2004): "Labour Market Institutions And Wage Inequality," IZA Discussion Papers, 1291.

Ljungqvist, L., and T. J. Sargent (2002): “The European Employment Experience," CEPR Discussion Paper, 3543.

Michalopoulos, C., P. K. Robins, and D. Card (2005): "When financial work incentives pay for themselves: evidence from a randomized social experiment for welfare recipients," Journal of Public Economics, 89, 5-29.

Moffitt, R. A. (2003): "The Negative Income Tax and the Evolution of U.S. Welfare Policy," Journal of Economic Perspectives, 17, 119-140.

Nickell, S. (2004): "Poverty and Worklessness in Britain," Economic Journal, 114, C1-C25.

Nickell, S., L. Nunziata, and W. Ochel (2005): "Unemployment in the OECD since the 1960s: What Do We Know?," Economic Journal, 115, 1-27.

OECD (2002): Benefits and Wages. OECD, Paris.

- (2004): Percentile distribution of gross earnings. http://www1.oecd.org/ scripts/cde/members/LFSDATAAuthenticate.asp. Download May 2005. OECD, Paris.

Phelps, E. S. (1994): "Raising The Employment And Pay Of The Working Poor: Low Wage Employment Subsidies Versus The Welfare State," American Economic Association Papers and Proceedings, 84(2), 54-58.

- (1997): Rewarding Work - How to Restore Participation and Self-Support to Free Enterprise. Harvard University Press, Cambridge, MA.

Pissarides, C. A. (1998): "The Impact of Employment Tax Cuts on Unemployment and Wages - the Role of Unemployment Benefits and Tax Structure," European Economic Review, 42, 155-183. 
— (2003): "Unemployment in Britain: A European Success Story," CESifo working paper 981 .

Saez, E. (2002): "Optimal Income Transfer Programs: Intensive versus Extensive Labor Supply Responses," The Quarterly Journal of Economics, 117, 1039-1073.

Schnabel, C. (2003): "Determinants of trade union membership," In: Addison, J.T., Schnabel, C. (Eds.), International Handbook of Trade Unions. Cheltenham: 13-43.

Schneider, H., K. F. Zimmermann, H. Bonin, K. Brenke, J. Haisken-DeNew, and W. Kempe (2002): "Beschäftigungspotenziale einer dualen Förderstrategie im Niedriglohnbereich. Gutachten im Auftrag des Ministeriums für Arbeit und Soziales, Qualifikation und Technologie des Landes Nordrhein-Westfalen," IZA Research Report, 5.

Snower, D. J. (1994): "Connecting Unemployment Benefits Into Employment Subsidies," American Economic Association Papers and Proceedings, 84, 65-70.

Sørensen, P. B. (1997): "Public Finance Solutions to the European Unemployment Problem," Economic Policy, pp. 222-264.

Thorbecke, E., and C. Charumilind (2002): "Economic Inequality and Its Socioeconomic Impact," World Development, 30, 1477-1495.

Van der Linden, B. (2004): "Active citizen's income, unconditional income and participation under imperfect competition: a welfare analysis," Oxford Economic Papers, 56, 98-117.

van der Ploeg, F. (2005a): "Do conditional benefits reduce equilibrium unemployment?," In J. Agell and P. Sørensen (eds.), Tax Policy and Labour Market Performance, CESifo and MIT Press, Cambridge, Mass.

(2005b): "Do social policies harm employment?," In J. Agell and P. Sørensen (eds.), Tax Policy and Labour Market Performance, CESifo and MIT Press, Cambridge, Mass.

There is a Referees' Appendix which is available upon request. 
Département des Sciences Économiques de l'Université catholique de Louvain

Institut de Recherches Économiques et Sociales

Place Montesquieu, 3

1348 Louvain-la-Neuve, Belgique 